\title{
BED TOPOGRAPHY, BED SHEAR STRESS DISTRIBUTION AND VELOCITY FIELD IN A CONFLUENCE
}

\author{
S. B. Weerakoon, Nobuyuki Tamai and Yoshihisa Kawahara \\ Dept. of Civil Engineering, Univ. of Tokyo, Tokyo 113.
}

\begin{abstract}
Laboratory experiment in 60-degree confluence was conducted using wellgraded sand under active bedload condition for a discharge ratio of 0.6 . The equilibrium channel bed was fixed and detailed measurements of mean flow were then carried out. Thereby, bed topography, two component velocity measurements, bed shear stress distribution and two counter rotating secondary flow cells are reported. Also, flow mechanism and bed morphology development in a confluence are explained. Bed shear stress maxima appear over the upward slopes along which bedload is transported away from the scour hole.
\end{abstract}

Keywords: bed topography, bed shear stress, confluence, scour hole, secondary flow

\section{Introduction}

River confluences where two upstream channel flows of different hydraulic conditions experience changes in channel alignments, mixing of two flows to form a single river channel of different hydraulic conditions are present in every river system. This adoption occurs in a comparatively short river length and is characterized by bed scour, bank erosion, bar formation and water surface superelevation. Therefore confluences are critical elements in a river system and thorough understanding of them is essential in flood control, irrigation systems, navigation etc.

The studies of river confluences have been reported by many researchers. Taylor(11) theoritically investigated the channel junction flow by one-dimensional approach. Two-dimensional theoritical approaches have been employed to predict the size of the recirculation zone as documented by Webber and Greated(12), Modi et.al(7) and Fujita and Komura(4). Moreover, three-dimensional numerical models of river confluence flows, based on $k-\epsilon$ turbulence model, are documented by Tamai and Ueda(10), Weerakoon and Tamai(14). These models have provided the detailed flow field with two counter rotating secondary flow cells. As for the experimental investigations, Best and Reid(3) reported the size of recirculation zone with discharge ratio, Fujita and Komura(5) documented detailed measurements of velocity in a 90-degree confluence. Tada(9) performed velocity measurements in a confluence with a training levee. Velocity field in a 60-degree confluence with a recirculation zone was documented by Weerakoon et.al(13).

The available studies under movable bed conditions are however very limited. Mosley (8) carried out detailed laboratory experiments on confluence scour under active bedload conditions. He observed the two back-to-back vortices that cause the lensshaped scour hole, and also the water surface superelevation over the scour hole. He also reported the increase of confluence scour depth with the increase of angle of incidence and discharge ratio. Also the decrease in scour depth with the increase of sediment load carried by the branch channels. Ashmore and Parker(1) analysed large amount of field and laboratory model data and reported that local geometry,i.e. the angle of incidence of the upstream branches, is the major factor for confluence scour and not valley parameters at all. They also found the influence of gradation and cohesivness of bed material in the reduction of scour depth. The possibility of modelling of gravel braided streams with low model Reynolds number, coarse noncohesive bed material has also been concluded. Best and Reid(3) investigated the sediment transport distribution in confluences and found that the strong helicoidal motions transport sediments from the upstream branches passing around the scour hole than through the center of it. 
In the present study, experiment was conducted under active bedload conditions and resulted bed topography, velocity and relative shear stress distributions at the equilibrium are provided. Thereby the flow mechanism in a confluence is explained.

\section{Experimental apparatus and procedure}

The experimental facility used in the present study is shown in fig. 1 where main channel and branch channel are of $50 \mathrm{~cm}$ and $30 \mathrm{~cm}$ widths respectively, and angle of incidence is 60 degrees. More details of the apparatus are found in reference (13). Wellgraded sand of median diameter of $1.6 \mathrm{~mm}$ was used in the experiment to avoid any ripple or dune formation. It was found by separate trials that bed slope of $1 / 200$ fits for the present experiments. Under the flat bed condition with $10 \mathrm{~cm}$ thick sand layer, the predetermined discharges were set at each upstreams. Sand was not recirculated, but continuously fed to upstreams at the entrances such a way that the feeding rate cause no aggradation or degradation at the upstream developing flow regions.

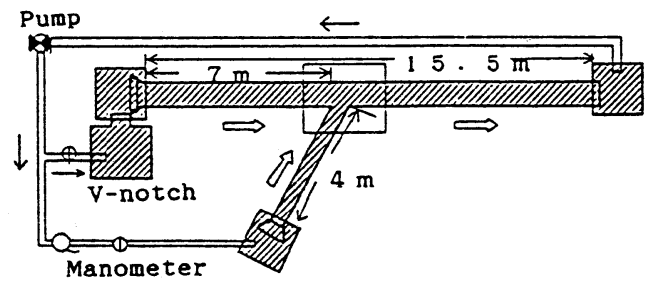

Fig. 1 Experimental apparatus

Main
channel $\begin{aligned} & \text { Tributary } \\ & \text { channel }\end{aligned} \begin{aligned} & \text { Post conf. } \\ & \text { channel }\end{aligned}$

Table. 1

Dynamic equilibrium was assumed to exist when, water surface elevation remained unchanged, bed topography had reached to a steady state and sand infeed rate at upstreams was equal to the collection rate at the outfall. The equilibrium condition was achieved in 2 hours and 15 minutes and corresponding hydraulic conditions are summerized in table 1. Depths and energy slopes given are of far upstreams and far downstream. The water surface elevation was measured and the flow was carefully stopped and allowed to drain slowly so that the channel bed was undisturbed. The bed was then carefully fixed by spraying very light cement grout. The resulted bed reproduced the hydrodynamic conditions satisfactorily and was thus employed for detailed measurements. Two-component velocity measurements were carried out by a $8 \mathrm{mmx30mm}$ magnetic currentmeter and shear stress measurements by a pitot tube with a 20 degree inclined manometer.

\section{Bed topography}

At the beginning stage, flow was over the flat bed and thus a flow pattern similar to Weerakoon et.al(13) was observed but changed very fast to appear bed scouring at the larger bed shear stress region associated with larger velocities near the downstream corner of the confluence. The recirculation zone began to smaller due to the deposition of sand by secondary flow. With time, scour hole gradually moved towards the upstream corner of the confluence while deepening. Sametime, the helicoidal motion and water surface superelevation in the scour hole became intense. Bars were developing in both upstreams due to the back-water effect of confluence. At a certain stage, they developed up to the scour hole avalanche surfaces and the whole channel bed became mobile. Sand supplied rates were maintained to agree with the equilibrium bed load transport rate for upstream channels because upstream sediment discharge is influential in confluence scour: larger the sediment discharge rate smaller the scour as found in $\operatorname{Mosley}(8)$. This can be understood because when more bedload is brought to the confluence flow should exert more shear stress to transport them and that is achieved by decreasing the water depth. 
At the equilibrium condition, flow is self-adjusted so that bed shear stress at any point on the bed is sufficient only to transport the sand supplied to that point. The upstream branch channel beds were flat but alternate bars were observed in postconfluence channel due to the existence of a confluence at upstream. The resulted bed topography contours in the confluence region are shown in fig.2 and the lens- shaped scour hole and avalanche faces that dip to the scour hole at the end of bars in both branches are clear as similar to the observations by Mosley(8) and Best and Reid(3). The scour depth observed here is in agreement with the scour depths reported for the same confluence angle and discharge ratio by Ashmore and Parker(1).

It should be noted that flat bed models show greater upsteam water depth due to the constriction of flow at the junction than the movable bed models where scour hole relaxes the constriction.

\section{Velocity field}

Figs.3a to $3 \mathrm{c}$ shows the velocity vectors in the confluence region at different levels according to the water depth. Fig.3d shows the velocity vectors of depth averaged flow computed from measurements. It should be noted that only two component measurements are available here despite the three-dimensional nature of flow, observed in the experiment. It is seen from fig.3a that velocity vectors are buldging over the scour hole forming a high pressure zone resulting water surface superelevation with high turbulence. Increased pressure in this region appears due to the counter balancing centrifugal forces of oppositely curving paths of fluid. It is interesting to note that this line of buldging is found to be directly above the centerline of the scour hole. It also shows that flows from both branches continue to take their paths upto buldging line with no prior lateral deflections. From figs.3b and $3 c$, it is found that flow follows avalanche surfaces with a low velocity as spreading from the upstream corner of the scour hole. The erosion near right bank of the main channel as in fig.2 is understood due to the secondary flow associated with the deflection of vectors(fig.3b) by the wall. In fact, natural streams after a confluence are not in alignment with any of the two upstream branches. Again, the velocity pattern in flat bed models which always shows a flow recirculation zone does not show similarity to observed velocity patterns here.

\section{Secondary flow}

Fig.4 shows secondary flow pattern in the scour hole taking the scour hole axis as the primary flow direction. It also shows the free surface superelevation. Two secondary flow cells rotating at opposite directions are evident in the confluence. They are due to the centrifugal forces associated with the deflection of flow and the strengths of them are proportional to the radius of curvatures and the squares of the velocities. They bring much of the flow and bedload from the scour hole towards the respective banks as depicted in figs.3 and 4. As whole water mass in the tributary undergoes greater deflection, a stronger secondary flow upto $80 \%$ of the velocity at the upstream is resulted as shown. This has caused a small sand bar to appear and thereby to reduce water depth and to disappear flow recirculation near the downstream corner. But, bed towards further downstream of the same bank is eroded by this flow. Rapid mixing of two flows from branches occurs only as they leave the scour hole. This strong mixing while flowing along the upward slope was observed to accompany with strong upward motions upto the surface.

It is observed that confluence flow shows strong three-dimensionality due to the presence of scour hole than a flat bed model can predict.

The effect of mixing in a confluence can be understood to appear on the channel bed in two ways. It increases the turbulence, hence the turbulent shear stress, and sametime it damps the secondary flow. By introducing a curved wall along the centerline of the scour hole where two flows can be reasonably devided, we found that bed scouring became more intense due to stronger secondary flows. Thus net effect of mixing was therefore to reduce the bed scouring in the present case. 


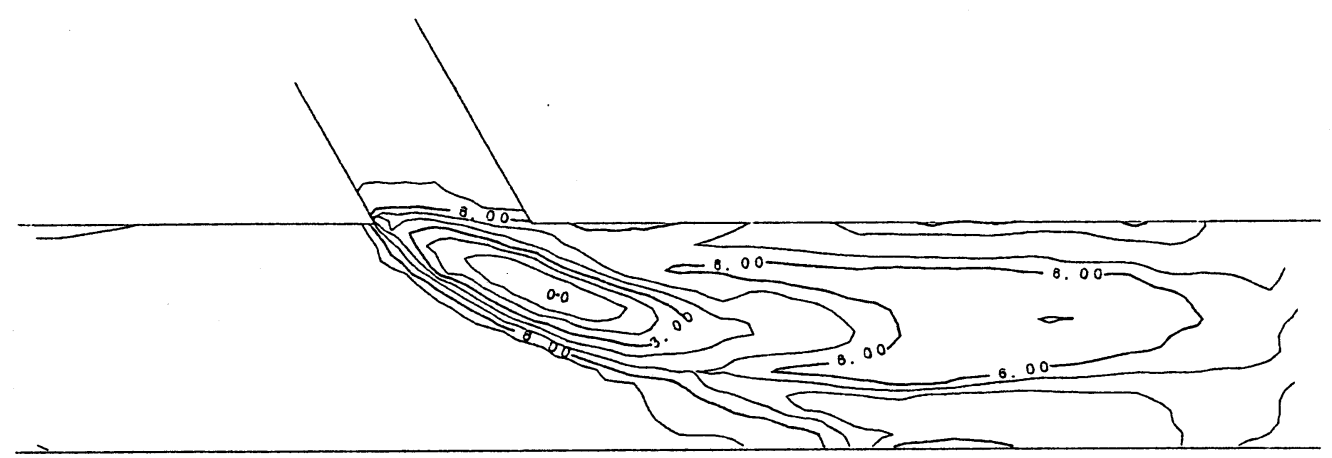

Fig. 2 Bed elevation contours (contour interval of $1 \mathrm{~cm}$ )

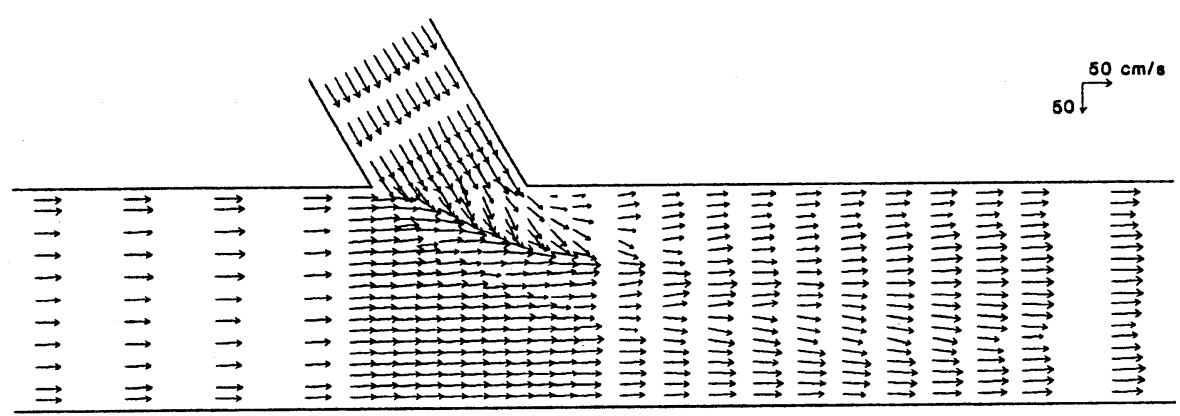

(a)

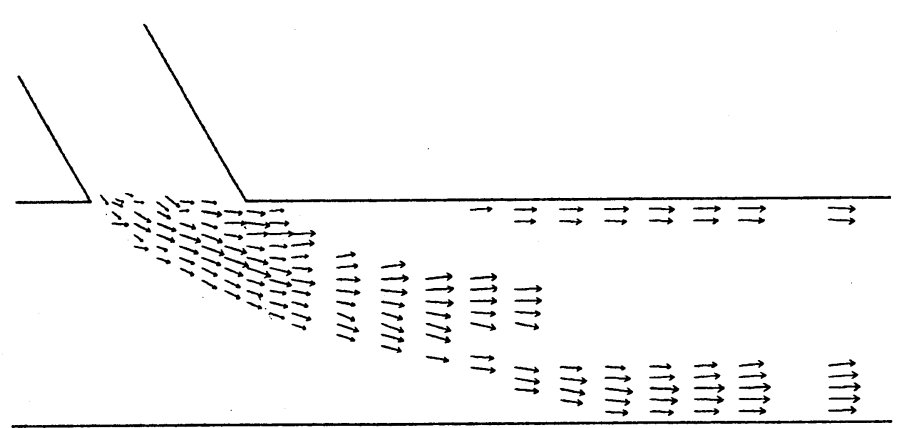

(b)

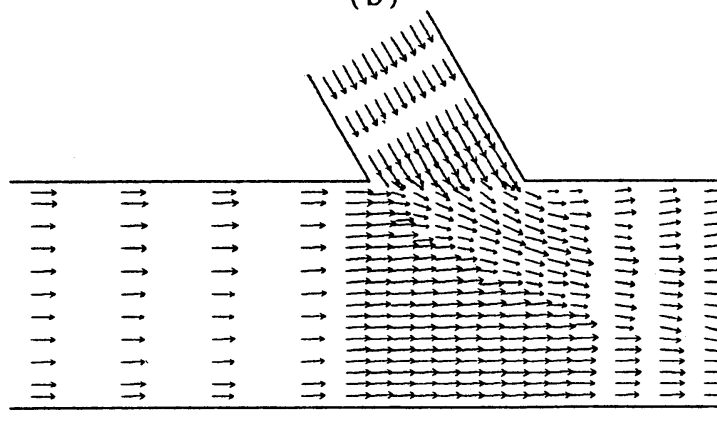

(d)

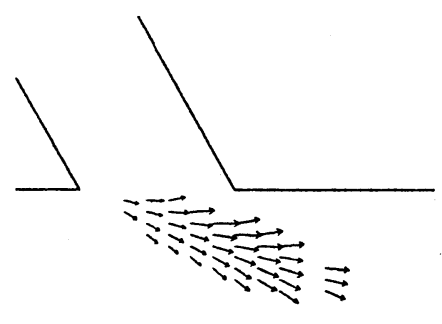

(c)

Fig. 3 Horizontal velocity vectors

(a) for upto $3 \mathrm{~cm}$ from the surface

(b) for $3 \mathrm{~cm}$ to $6 \mathrm{~cm}$ from the surface

(c) for $6 \mathrm{~cm}$ to $9 \mathrm{~cm}$ from the surface

(d) depth-averaged 


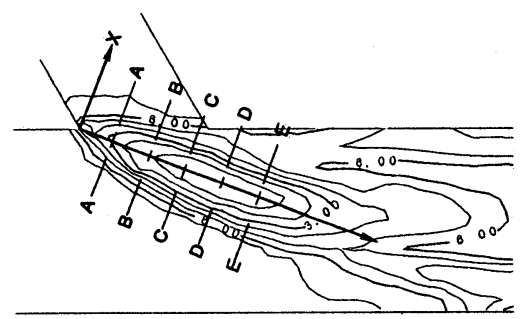

(a) SECTION LAYOUT

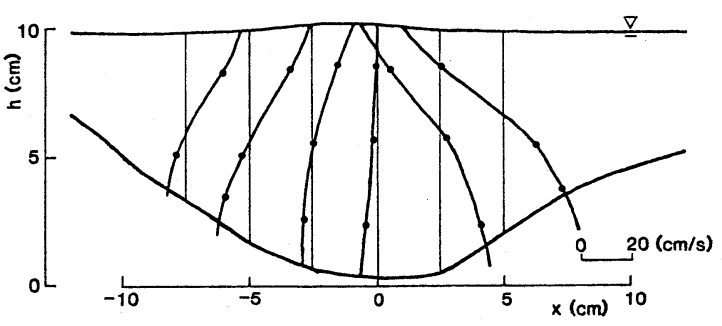

(d) SECTION C-C

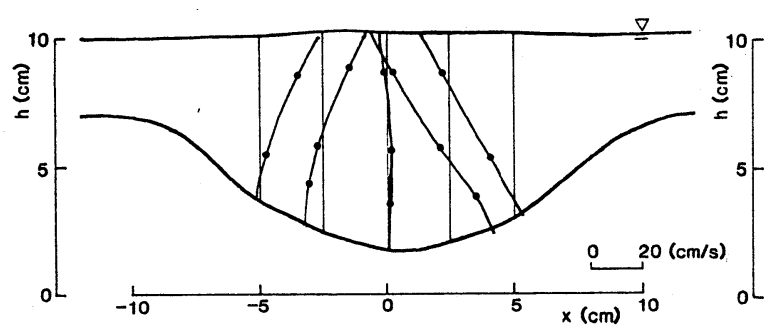

(b) SECTION A-A

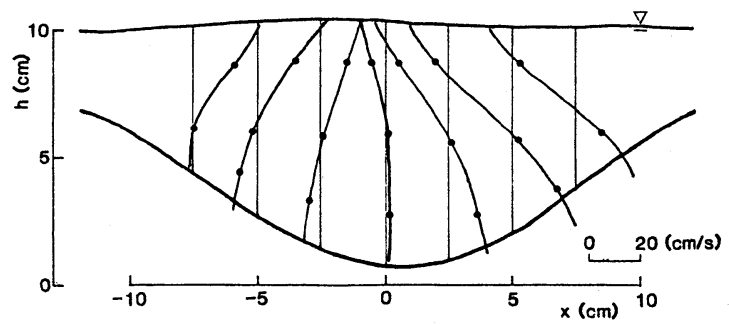

(c) SECTION B-B

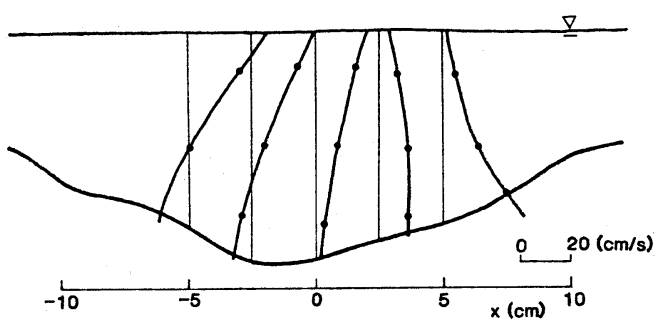

(f) SECTION E-E

Fig.4 Secondary flow in the scour hole

\section{Bed shear stress distribution}

Bed shear stress measurements over the fixed bed were carried out similar to Hooke(6), but using a pitot tube, where the bed shear stress was assumed to be proportional to the dynamic pressure. The assumption is however not well convinced due to the complex nature of flow with variable pressure gradients and the surface roughness. The pitot tube was always kept lying over the surface and directed against the flow by viewing the flow direction by a tuft. The positioning on the slope was however caused deviation from the flow direction due to the vertical velocity component and this could have produced an error upto $20 \%$. The measurements were reproducible. The relative bed shear stress distribution is depicted in fig.5. Shear stress minima appear on both avalanche faces over which velocities were also small although no leeward eddies were observed. The strong secondary flow which brings high velocity water at the surface has caused shear stress maxima, upto 5 times the mean shear stress of the upstream channels, to appear over the upward slope of the scour hole where flow leaves it. This meets the requirement of flushing the bedload accompanied by flow along the upward slope. Due to the two counter rotating secondary flow cells, shear stress along the centerline of the scour hole shows lower value than sorrounding and thus the bedload transport along the center of the scour hole is low. The larger values again appear at downstream right bank where flow is along an upward slope after deflection by the wall. 


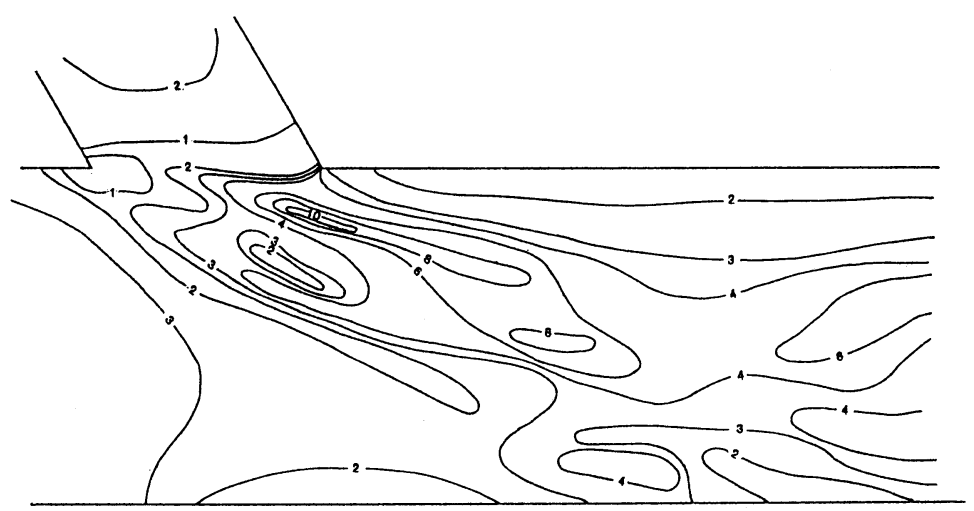

Fig.5 Relative bed shear stress contours

\section{Conclusions}

Three-dimensional flow structure in a confluence associated with secondary flow, mixing, free surface superelevation and complex bed geometry is demonstrated by the experimental results at equilibrium condition under active bedload.

a) The existence of scour hole, sand bars in both upstream branches and at the downstream corner of the confluence, and the erosion of downstream banks are shown.

b) Free surface superelevation appear over the scour hole due to the pressure increase associated with the counter balancing centrifugal forces of the two oppositely curving fluid paths.

c) Two counter rotating secondary flow cells due to the streamline curvature maintain the scour hole and transport larger mass of flow towards the downstream banks.

d) Relative shear stress distribution indicates local maxima of 5 times the mean shear stress of the upstream channel, and larger bedload transport towards the banks.

\section{References}

1. Ashmore,P.and G. Parker: Confluence scour in coarse braided streams, J.of Water Resources Research, Vol.19, No.2, pp.392-402, 1983.

2. Best, J.L.: Sediment transport and bed morphology at river channel confluences, J. of Sedimentalogy, Vol.110, No.11, pp.487-498, 1988.

3. Best, J.L. and I. Reid : Separation zone at open channel flow junctions, J. of Hydr. Engrg., ASCE, Vol.110, No.11, pp.1588-1594, 1984.

4. Fujita, I. and S. Komura: Application of free streamline theory tothe flow in a river confluence, 5 th congress, APD-IAHR, pp.103-120, 1986.

5. Fujita, I.and S. Komura: Visualization of the flow at a river confluence, Proc.of 3rd Int. Symp. on Ref. flow Mod. and Turb. Meas., pp.61-618, 1988.

6. Hooke, R. Le B.: Shear stress and sediment distribution in a meander bend. Univ. of Uppsala, Sweden, Ung Report. No.30, 58p.

7. Modi, P.N., P.D. Ariel and M.M. Dandekar: Conformal mapping for channel junction flow, J. of Hydr. Div., ASCE, Vol.107, HY12, pp.1713-1733, 1981.

8. Mosley, M.P: An experimental study of channel confluences, J. of Geology, Vol.94, pp.535-562, 1976.

9. Tada, H.: Experimental report, Osaka College of Technology, 1987.

10. Tamai, N. and S. Ueda: Prediction of flow behaviour at a river confluence by the $k-\epsilon$ model, Proc. 31st Jap. Conf. on Hydr., pp.437-442, 1987.

11. Taylor, E.H.: Flow characteristics at rectangular open channel junctions, Trans., ASCE, Pap. No.2223, pp.893-912, 1944.

12. Webber N. B. and C. A. Greated: An investigation of flow behaviour at junction of rectangular channels, Proc.of Inst.Civil Engrs., Vol.34,1966.

13. Weerakoon,S.B.,T.Imasato,T.Tamai,Y.Kawahara,Y.Hirosawa: Flow measurement at a 60 deg. confluence, 44th Annual Conf. of JSCE,pp.406-407,1989.

14. Weerakoon, S.B. and T.Tamai: Three-dimensional calculation of flow in confluences using boundary-fitted coordinates,JHHE,Vol.7,No.1,pp.51-62,1989. 